\title{
The Private Eye
}

\section{Brian K. Vaughan, Marcos Martín y Muntsa Vicente}

Panel Syndicate, 2014

$\mathrm{R}$

ESULTA cuanto menos curioso que un hombre que huye de las hoy omnipotentes redes sociales, que no tiene twitter, ni facebook, cosa casi obligada hoy en día para un artista como medio de promoción, sea el responsable de llevar el cómic digital a un nuevo nivel escribiendo un cómic que habla precisamente sobre el peligro de internet y las redes sociales. Todo un poco irónico. Que el cómic digital es algo que no termina(ba) de arrancar parece claro, los diversos modelos que se han puesto sobre la mesa no han logrado involucrar al público y, a pesar de que todas las grandes editoriales disponen de su propio catálogo de cómics digital y fomentan y promocionan el mismo, es un negocio que no llega a ser tan rentable como algunos pensaban. Desde luego no es la panacea, ni el futuro de la industria. Ni mucho menos el presente. Al final ha resultado ser, mal que les pese a los gurús, un nicho de mercado más, igual que pueden ser los quioscos o las grandes superficies, una opción más de la que el aficionado puede disponer.

Pero el gran acierto de Brian K. Vaughan y Marcos Martín no es la reinvención del cómic digital, aunque a ello también han contribuido notablemente, sino la demostración de que otro modelo de negocio es posible para el cómic llamémosle "americano" y por extensión, como ya es una realidad en la misma Panel Syndicate con el Universe! de Albert Monteys demuestra para cualquier otro tipo de cómic. Panel Syndicate es la prueba viviente de que el modelo de negocio clásico de autor-editorial-distribuidora-librería-lector ya no es ni mucho menos el único posible y han creado uno en el que la obra recorre el camino directo desde el

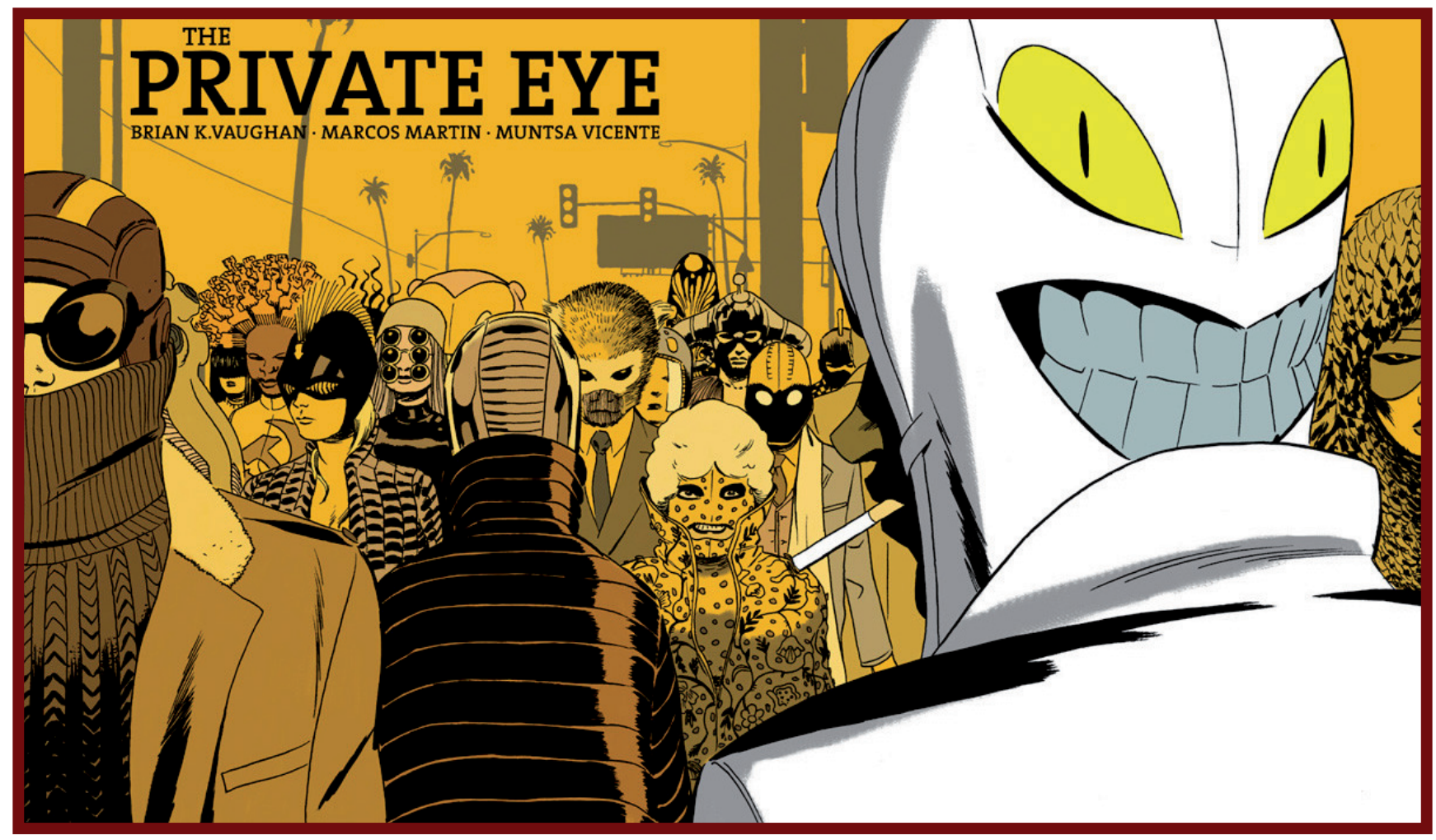




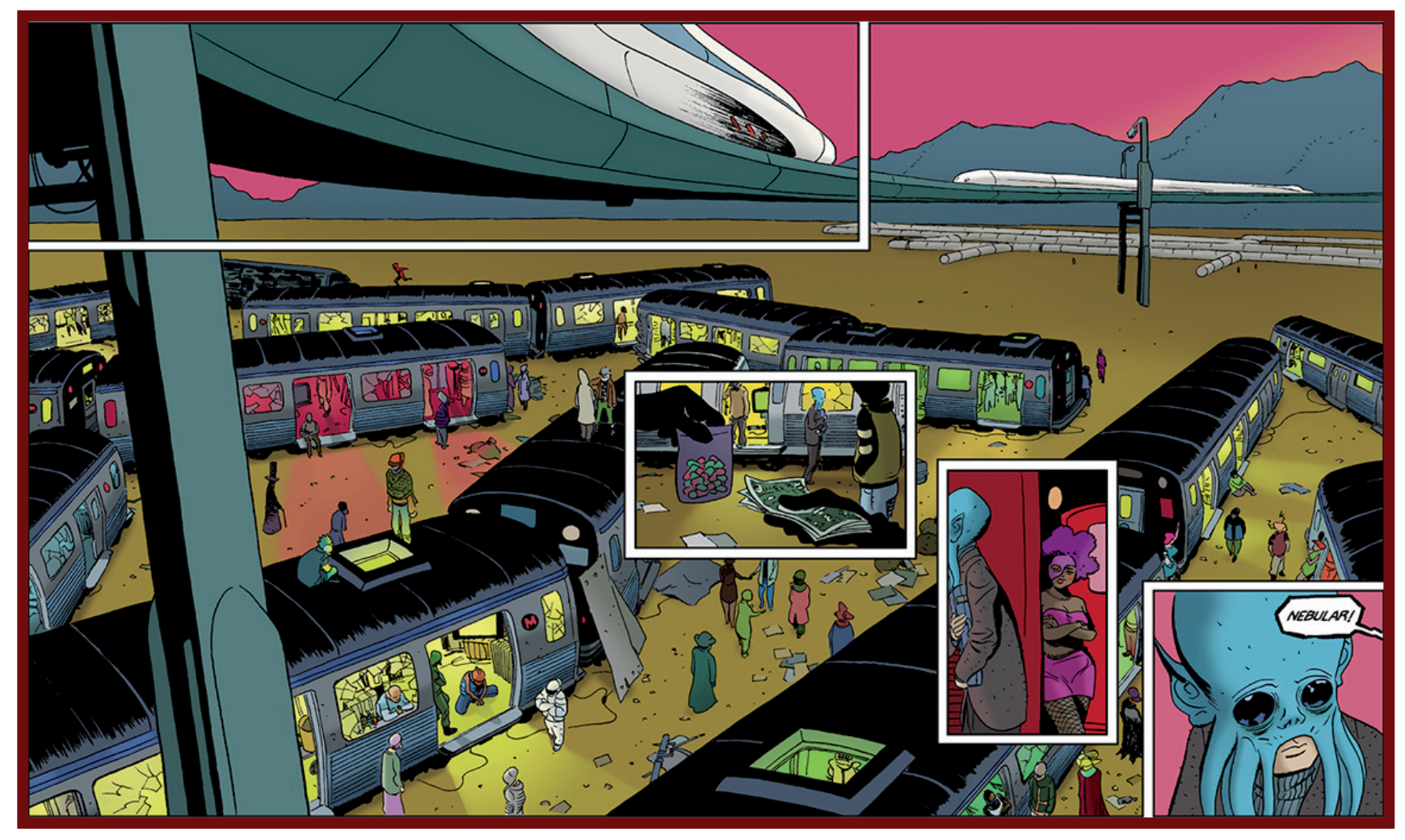

autor al lector sin ni un solo intermediario y permitiendo que sea el lector (no el mercado, ni la editorial, ni el gobierno) quien ponga el precio según su propia conciencia y su reconocimiento del trabajo de los autores que han hecho posible el cómic. Esto, que podría parecer una locura inviable nacida de la mente de un par de autores cabreados con la industria, parece ser un modelo de negocio legítimo y perfectamente funcional que puede - $\mathrm{y}$ de hecho ya lo está haciendo con ejemplos en nuestro propio país- abrir el camino a otros autores a canalizar su arte por esta vía. El camino que Vaughan y Martín han tomado es un camino valiente y arriesgado, pero brutalmente honesto: "esto es lo que yo te ofrezco, dime cuánto crees que vale". Y el público, que no es tonto, ni un hatajo de ladrones amantes del todo gratis como algunos quieren hacernos creer, parece responder positivamente a la propuesta.

Por supuesto, esto no sería posible si el cómic planteado no tuviera un mínimo de calidad, y The Private Eye calidad tiene a raudales. La historia plantea un futuro distópico en el que en un momento determinado "la nube" explotó, y toda esa información que guardamos en internet, en nuestro historial de búsqueda, en nuestra cuenta de correo, en nuestra cuenta de dropbox, se hizo pública permitiendo a cualquier persona disponer de cuanta información quisiera sobre cualquier otra. No podemos pasar por alto el símil con la situación actual, en la que el umbral de privacidad de la sociedad está llegando a unos niveles tan bajos en los que sin necesidad de esta "explosión de internet" volcamos información privada en cantidades masivas en la red, disponible para cualquiera con la paciencia para recuperarla. En menos de una hora un usuario medio podría obtener el nombre de nuestros familiares y amigos, nuestra dirección y una lista de gustos bastante acertada, amén de los lugares que más visitamos y las horas a las que estamos o no en nuestra casa, y eso tan solo es el principio. Lo que Vaughan y Martín plantean es menos ciencia ficción de lo que parece. The Private Eye nos cuenta como, llegados a ese punto, la sociedad dio un brusco giro de $180^{\circ}$ hasta una cultura de la hiperprivacidad en la que nada es lo que parece y nadie quien dice ser. Con este tapiz de fondo, Vaughan plantea un thriller detectivesco en toda regla con su investigador privado, su mujer misteriosa, su asesinato al comienzo del relato y todos los clichés del género que uno pudiera desear, pero articulados de modo que forman una narración tremendamente original y atractiva.

Generalmente en los cómics creados a cuatro manos suele haber una persona que destaca, acaso involuntariamente, sobre el global, sea el guionista o sea el dibujante, a menudo es uno de los dos el que más importancia tiene en el resultado final, el que imprima ese regusto último que hace al cómic ser lo que es. 
Esto es algo imposible de afirmar en The Private Eye, si el guión de Vaughan plantea una aventura trepidante y misteriosa con un ritmo frenético, el dibujo de Martín resulta totalmente indispensable para hacer del cómic lo que es creando no solo un universo nuevo y fascinante sino adaptándolo además al formato en el que es presentado, otro de los grandes aciertos de The Private Eye. No todos los autores son capaces de detectar las particularidades de un formato y construir su cómic basándose en ellas a fin de obtener el máximo rendimiento y beneficio de las mismas. Si el cómic digital no termina de funcionar es porque no deja de ser el mismo cómic de papel pero presentado en la pantalla del ordenador, lo que lo hace no solo más incómodo de leer según el dispositivo en el que lo leas, sino que le hace perder las particularidades intrínsecas del formato en el que ha sido creado. Leer en la pantalla de un ordenador o tablet no es ni remotamente parecido a leer en papel, igual que leer un cómic en formato apaisado no se asemeja a leer un cómic en formato comic-book americano. Es obligación del artista saber cómo va a ser presentada su obra y adaptarla en consecuencia, algo que Vaughan y Martín han comprendido a la perfección desde el primer número haciendo que The Private Eye "sea" un cómic digital, y no pueda existir de ningún otro modo.

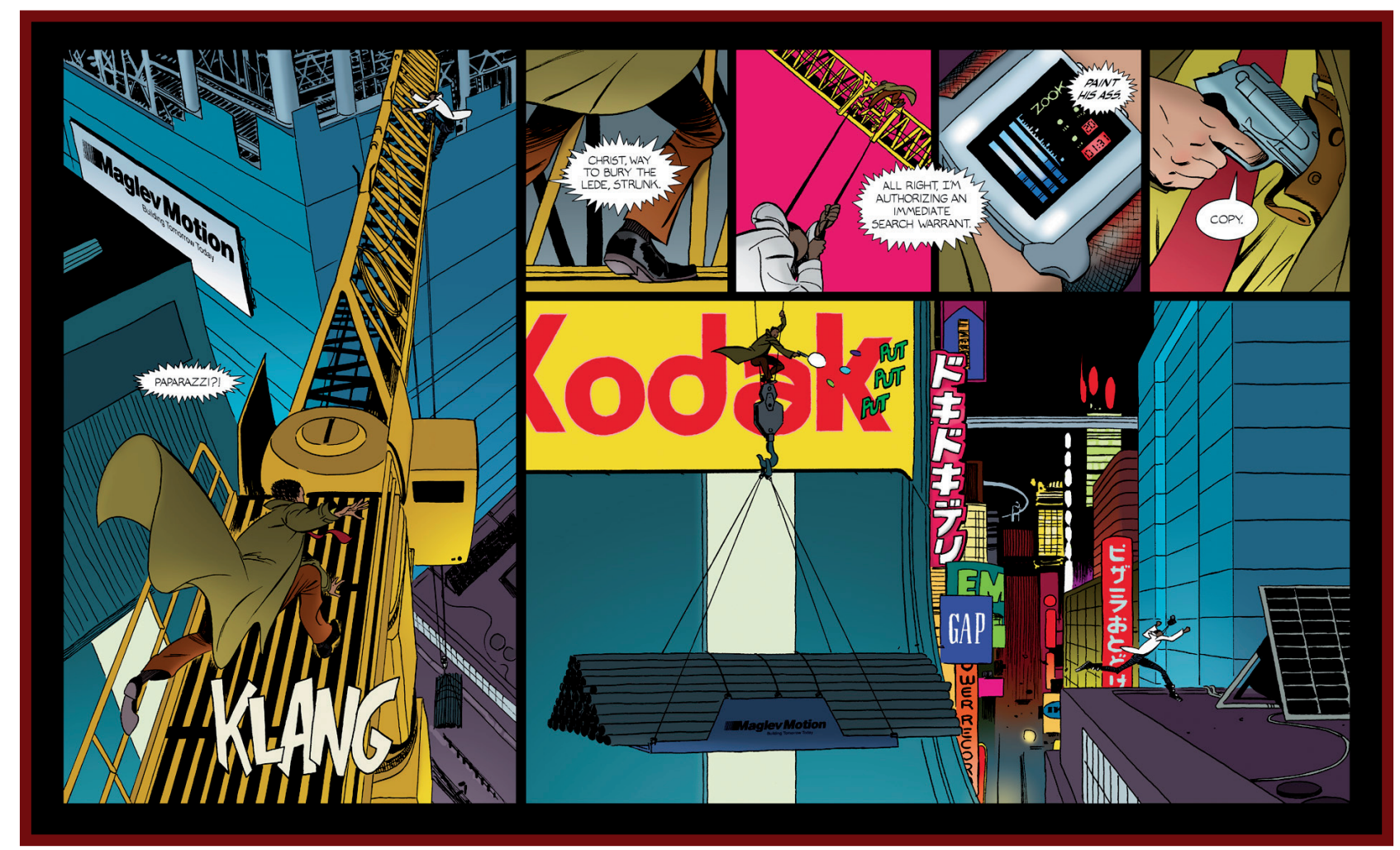

Por tanto, The Private Eye no solo es un cómic fascinante, divertido, original, y maravillosamente dibujado, sino que tiene una importancia particular en la historia del medio por su acertadísimo entendimiento del formato en el que se presenta sabiendo adaptar su historia mejor que nunca a las peculiaridades de lectura del cómic digital, y por la demostración de que otro modelo de negocio es posible en la industria del cómic, un modelo en el que los autores crean sus obras y las envían directamente a sus lectores sin intermediarios ni costes adicionales, afianzando la relación autor-lector y haciéndola más cercana que nunca. Solo queda preguntarse lo que podrían lograr desde Panel Syndicate si hicieran un uso masivo de las redes sociales para promocionarse como tantos otros hacen, claro que entonces perderían privacidad y autenticidad.

Borja Usieto

Borja Usieto se sumergió por primera vez en internet con $\mathrm{El}$ Imaginario del Dr. Ender, un blog de crítica cinematográfica que le dio el impulso necesario para comenzar en 2011 Quién Vigila al Dr. Ender, blog de cómic que acoge desde el tebeo más independiente hasta la última creación de Marvel, y que lo ha llevado a colaborar con algunas de las principales webs especializadas del medio. También podéis seguirlo en Twitter en @DocEnder. 